\title{
Influence of PV Penetration on Distribution Transformer Aging
}

\author{
Banu Uçar, Mustafa Bağrıyanık, and Güven Kömürgöz
}

\begin{abstract}
Increasing power demand urged countries to seek out energy sources with higher efficiency and lower cost than the existing ones. Solar energy is an effective alternative source to the traditional energy sources. The photovoltaic distributed generation is an effective energy source since it combines the advantages of smart grid and solar energy. Depending on the season, photovoltaic generation connected to the distribution network shows different penetration that affects the network load distribution, which can lead to excessive loading at lines, cables and transformers in distribution systems. As the life expectancy of transformers and cables in the distribution system depends on the operating conditions, overloading caused by penetration of distributed photovoltaic systems speeds up the aging of the components. Therefore, investigating the effects of photovoltaic systems on the aging is important for providing insight on the efficient use of components in the distribution transformers. In this study, the impact of loss of life on the distribution transformer photovoltaic production is examined by taking the seasonal influences into account from the point of view of a consumer.
\end{abstract}

Index Terms-Distribution transformer, aging and photovoltaic generation.

\section{INTRODUCTION}

Globally, there is an increases in load demand and an exhaustion of traditional energy sources. Environmental sensitivity, such as restrictions on carbon dioxide emissions has led to an increase in energy production that uses renewable energy sources [1]-[3]. One of the renewable energy sources is the photovoltaic production, and the interest in it has increased significantly in recent years, in parallel with the development of photovoltaic technology. In a report released in 2010, it was announced that solar energy production target of the Europe for 2020 is $84.4 \mathrm{GW}$. When Germany has $20,7 \mathrm{GW}$ solar power capacity in 2012, planned solar power is $51.8 \mathrm{GW}$ in 2020 [4].

Increasing the number of photovoltaic production units connected to the network has led to a need for examining the effects of the distribution system [1]-[3]. Photovoltaic systems can cause voltage fluctuations due to the changes on the solar energy. It also causes power factor problems due to active power changes in the system. In addition, as the photovoltaic systems were designed as unidirectional, protection plans are affected when the network operates in

Manuscript received June 2, 2015; revised January 23, 2016

The authors are with the Electrical Engineering Department, Technical University of Istanbul, Turkey (e-mail: ozturkbanu@itu.edu.tr, bagriy@itu.edu.tr, komurgoz@itu.edu.tr). bidirectional power flow mode. Single-phase photovoltaic production due to unbalanced distribution system is a voltage imbalance between the phases [1], [5].

Transformers are important element in electrical power grids, in terms of both reliability and costs. Although they are extremely energy efficient, heat dissipation is a limiting factor for the maximum loading of transformers. The reliable operation of distribution systems is critically dependent on detailed understanding of load impacts on distribution transformer insulation systems. When transformers are operated in an overloaded mode, it speeds up aging and causes an increase in the probability of major failures.

In this study, the effects of the rooftop photovoltaic production in summer and in winter seasons on the useful life of distribution transformer have been studied. Variation in loss of life of distribution transformer was examined by taking the seasonal influence of PV penetration into account. Daily load profiles are used to determine the transformer's loss of life.

\section{REDUCTION IN THE USEFUL LIFE OF TRANSFORMERS}

The dielectric insulating properties of the insulation material may weaken if transformers are exposed to the temperatures above the limiting values. The insulation ages more rapidly, reducing its normal life. According to the IEEE C57.91-1995 guide, the life of the insulation is equal to the overall life of a transformer [6]. The guide leads the calculation of the winding hottest-spot temperature, which is the driving factor for limiting temperature overloads. Ratings such as the loss of life and the winding hottest-spot temperature can be used by system operators during contingency conditions, which will allow them to overload transformers for a definite time.

The most important parameters that influence the transformer useful life is the hottest-spot temperature $\left(\Theta_{H}\right)$. The relationship between the hottest spot temperature and the transformer useful life is obtained by using the experimental results and the Arrhenius reaction theory given in an IEEE standard, which is shown below:

$$
\text { Per unit life }=A \cdot \exp ^{\left[\frac{B}{Q_{H}+273}\right]}
$$

where, $Q_{H}$ is hot-spot temperature $\left({ }^{\circ} \mathrm{C}\right), \mathrm{A}$ and $\mathrm{B}$ are the constants. While hot-spot temperature is below $110^{\circ} \mathrm{C}$, transformer life is calculated as $1 \mathrm{pu}$ [6]. As a result of conducted experiments, constant $\mathrm{A}$ and $\mathrm{B}$ in standards are found as $9.8 \times 10^{-18}$ and 15000 respectively. Fig. 1 shows the change of the life with respect to hottest spot temperature. 


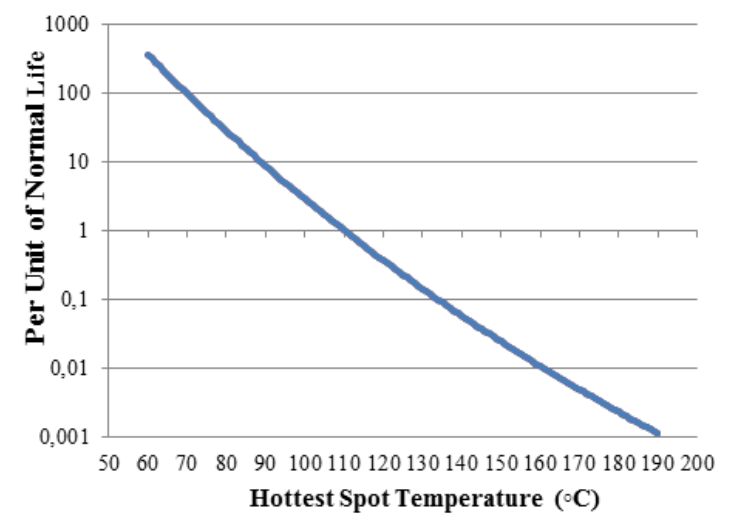

Fig. 1. Variation of the per unit life with the hottest spot temperature.

Aging acceleration factor is used to compare aging speed of transformer at $110^{\circ} \mathrm{C}$. Relative aging rate of the transformer insulation for given load and temperature values, can be determined as follows;

$$
F_{A A}=e^{\left[\frac{15000}{383}-\frac{15000}{Q_{H}+273}\right]}
$$

Aging acceleration factor is equal to 1 at $110^{\circ} \mathrm{C}$. Aging rate is greater than 1 for higher temperatures and less than 1 for lower temperatures. The given graph in Fig. 2 shows change of the aging acceleration factor with respect to hottest spot temperature. For calculation of the loss of life of transformer, hottest-spot temperatures must be defined. Hottest-spot temperature could be calculated with high accuracy by using the results of the experimental methods.

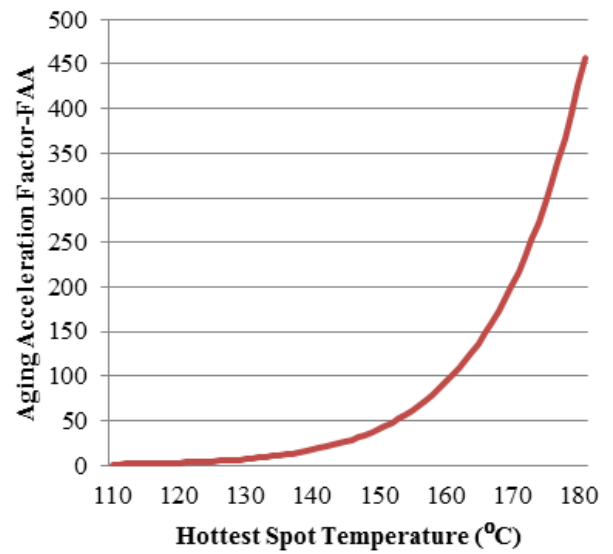

Fig. 2. Variation of aging acceleration factor with the hottest-spot temperature.

Hottest-spot temperature could be predicted by using thermal models from standards with top layer's temperature, load status and ambient temperature. If top layer's temperature is not available, hottest-spot temperature could be predicted with top-layer temperature, load status and ambient temperature.

IEEE C57.91-1995 standard is modeling change of temperature with respect to the change of load. Calculation of top-oil temperature, which is created by change of loads, and hottest-spot temperature is simplified. Changes of temperature could cause change of oil viscosity. To take account of load loss and change of oil viscosity, $m$ and $n$ constant are included to equations. Depending on the type of cooling, value is between 0 and 1 .
Hottest-spot temperature $\left(\Theta_{H}\right)$ is the sum of ambient temperature $\left(\Theta_{A}\right)$, top layer oil temperature change compared to the ambient temperature $\left(\Delta \Theta_{T O}\right)$ and winding temperature change compared to the oil temperature $\left(\Delta \Theta_{H}\right)$.

$$
\begin{gathered}
\Theta_{H}=\Theta_{\mathrm{A}}+\Delta \Theta_{T O}+\Delta \Theta_{H} \\
\Theta_{T O}=\Theta_{\mathrm{A}}+\Delta \Theta_{T O}
\end{gathered}
$$

Change of top oil temperature depending on change of loads can be obtained as given in Eq. 5 .

$$
\begin{gathered}
\Delta \Theta_{T O}=\left(\Delta \Theta_{T O, u}-\Delta \Theta_{T O, i}\right)\left(1-\exp ^{-\frac{t}{\tau_{T O}}}\right)+\Delta \Theta_{T O, i} \\
\Delta \Theta_{T O, i}=\Delta \Theta_{T O, R}\left[\frac{\left(K_{i} R+1\right)}{(R+1)}\right]^{n} \\
\Delta \Theta_{T O, u}=\Delta \Theta_{T O, R}\left[\frac{\left(K_{u} R+1\right)}{(R+1)}\right]^{n}
\end{gathered}
$$

The increase in the hottest-spot temperature depends on load and time and can be defined as follows;

$$
\Delta \Theta_{H}=\left(\Delta \Theta_{H, u}-\Delta \Theta_{H, i}\right)\left(1-\exp ^{-\frac{t}{\tau_{W}}}\right)+\Delta \Theta_{H, i}
$$

First and last value of the change of top oil temperature:

$$
\begin{gathered}
\Delta \Theta_{T O, i}=\Delta \Theta_{T O, R}\left[\frac{\left(K_{i} R+1\right)}{(R+1)}\right]^{n} \\
\Delta \Theta_{T O, u}=\Delta \Theta_{T O, R}\left[\frac{\left(K_{u} R+1\right)}{(R+1)}\right]^{n}
\end{gathered}
$$

\section{Photovoltaic Production}

The active power and power flow of a grid with photovoltaic production (PV) and domestic house consumers are shown in Fig. 3.

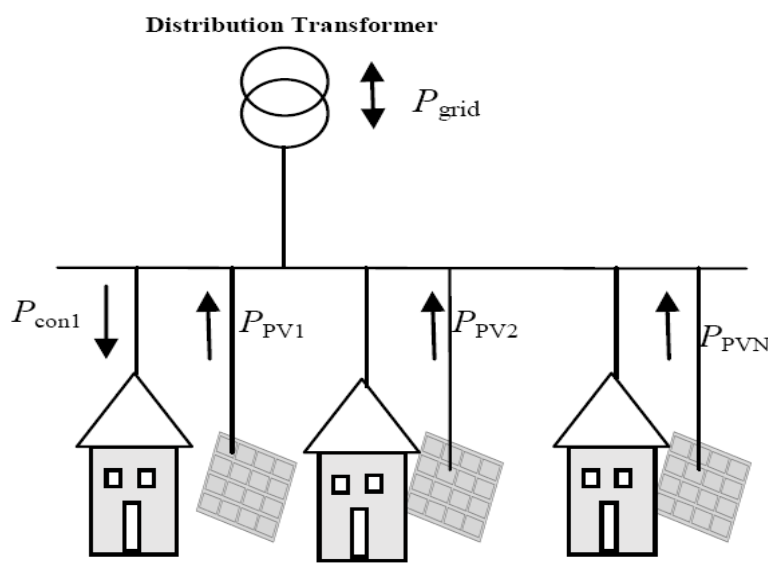

Fig. 3. Domestic house type grid with PV energy production. 
Net value of the power drawn from the transformer can be calculated as:

$$
P_{\mathrm{tr}, \text { net }}=\left(\sum_{i=1}^{n_{t}} P_{\mathrm{con}, i}+\sum_{i=1}^{n_{g}} P_{\mathrm{loss}, i}\right)-\sum_{i=1}^{n_{\mathrm{FV}}} P_{\mathrm{PV}, i}
$$

where, $P_{\mathrm{con}, i}$ is consumption of the domestic house consumer, $P_{\text {loss }, i}$ is loss of energy on the line component, $P_{\mathrm{PV}, i}$ is $\mathrm{PV}$ unit production, $P_{\text {tr,net }}$ value is effect on the loading of the transformer.

\section{CASE StUdy}

To study the aging effects of the photovoltaic systems on the distribution transformer, the loss of life is examined by taking into account the effects of seasonal changes by using a sample grid. In this study, the data from the photovoltaic panels in Istanbul Technical University in year 2009 are used. Taking these data into account, a system of 1000 consumers with $5 \mathrm{~m}^{2} 500 \mathrm{~W}$ roof type panels, supplied through a distribution transformer is designed [7].

The change of the load profile and the power consumption from the transformer in July and January nin a span of 24 hours and the PV production are given in Fig. 4 and Fig. 5. While the PV production in the summer supplies a considerable portion of the demand, in January this ratio is very low. The power consumption is normalized according to a 2MVA transformer's power. The effect of photovoltaic participation of transformer life in July 2009 to investigate the air temperature were obtained from the Meteorological Service.

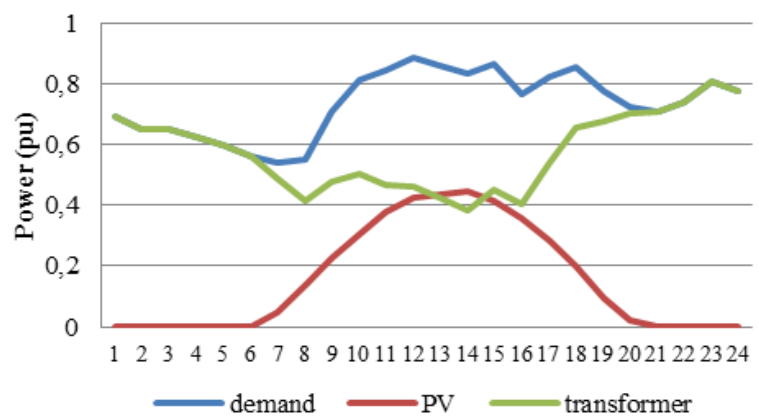

Fig. 4. The demand, photovoltaic production and power consumption from the transformer on 1st of July.

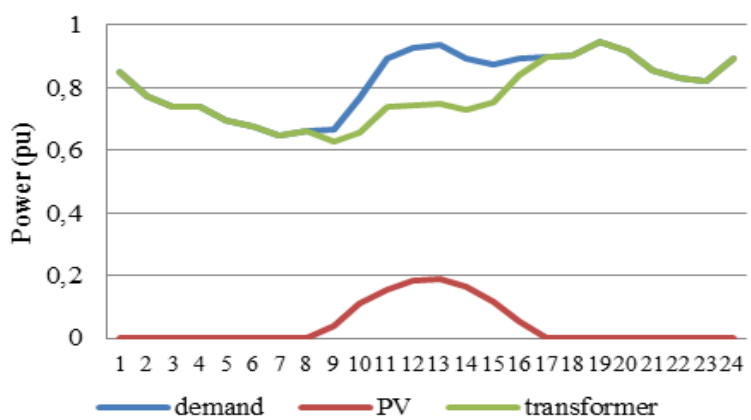

Fig. 5. Demand of January 20th, and the change of power drawn from the transformer photovoltaic production.

Demand scenarios were created in July, the power drawn from the transformer value and PV production values are given in the graph in Fig. 6. The positive contribution of PV production tothe transformer load is observed in July.

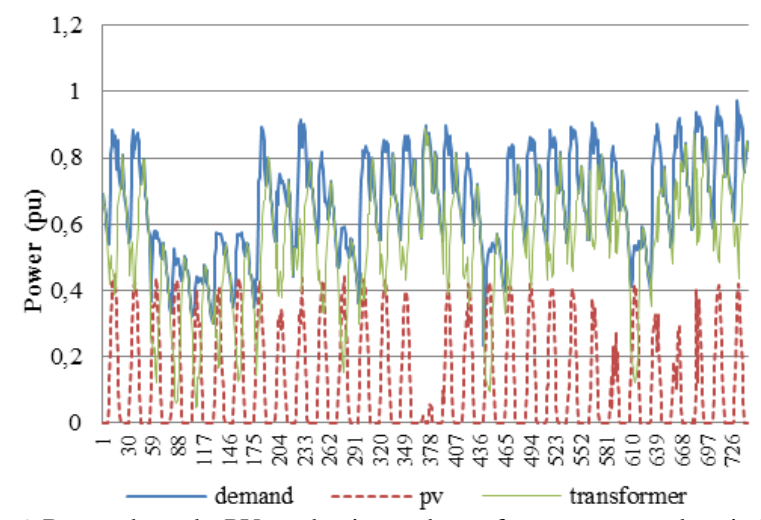

Fig. 6. Demand trends, PV production and transformer power values in July

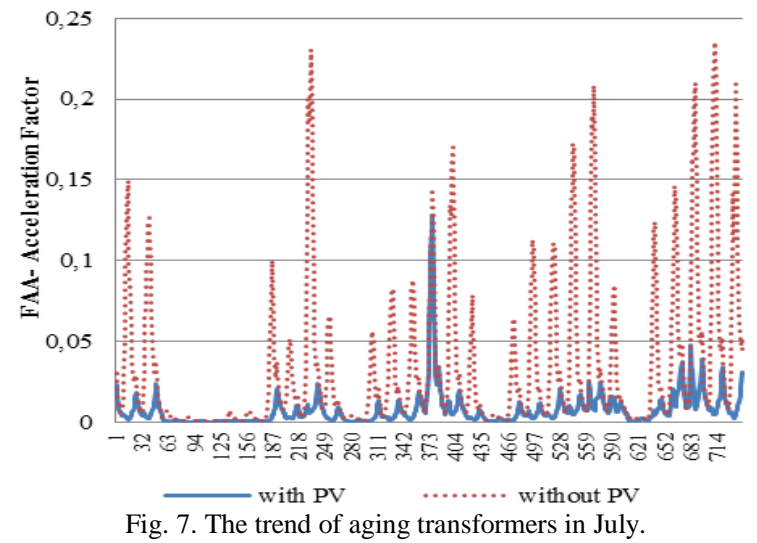

The aging rate for 2000kVA distribution transformers and their impact on the total aging rate is calculated. Having photovoltaic production, the trend of aging transformers in July is presented graphically in Fig. 7. Depending on aging rate is seen as falling PV production. Changes in the total expected life time is given in Fig. 8 and Fig. 9 for the cases with and withoutPV production. PV output transformer appears to have a positive effect on the total aging rate.

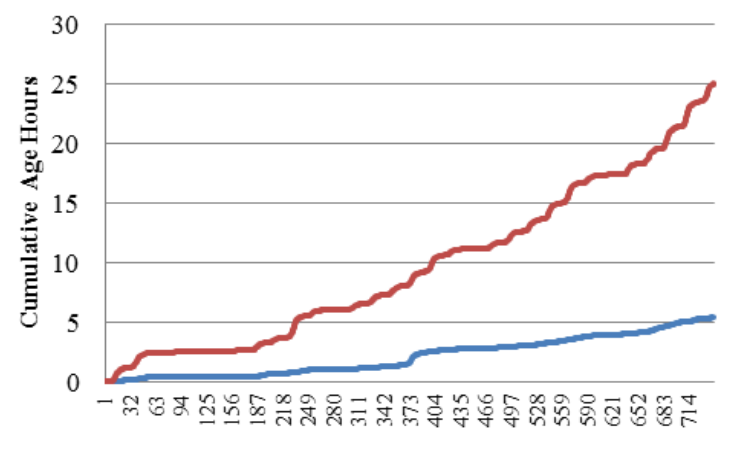

Fig. 8. Variation in the cumulative age hours in July.

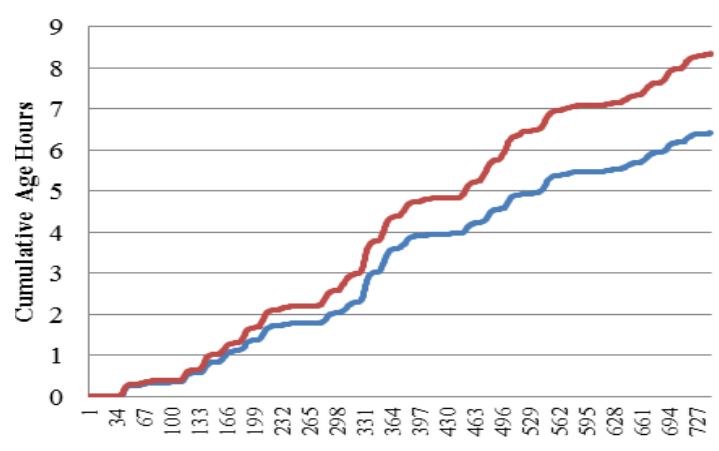

Fig. 9. Variation of cumulative age hours in January. 


\section{CONCLUSION}

Power transformers are an important element and the photovoltaic generation is one of the useful source choices in electrical power grids. Common sense and good planning is required to keep the economic gains in balance with the risks of failure in grid systems. The reliable operation of distribution transformers is critically dependent on detailed understanding of load impacts on distribution transformer insulation systems. In this study, the effects of the rooftop photovoltaic production on distribution transformer useful life have been studied taking the seasonal influences into account. It has been shown that PV is an important effect in grid system and it can significantly extend the transformer life. The use of a solar PV power system will be even more beneficial. Under load demand, production of distributed generation systems based upon renewable energy sources has a positive effect on the ageing of transformer aging. However, over the load demand local production causes reverse direction power flow These have a negative effect on transformer aging that must be investigated.

\section{REFERENCES}

[1] T. Gonen, Electric Power Distribution Engineering, 2nd ed. CRC Press, 2008.

[2] S. M. M. Agah and H. A. Abyaneh, "Distribution transformer loss of life reduction by increasing penetration of distributed generation," IEEE Transaction on Power Delivery, vol. 26, no. 2, April 2011.

[3] S. M. M. Agah and H. A. Abyaneh, "Qualification of the distribution transformer life extension value of distributed generation," IEEE Transaction on Power Delivery, vol. 26, no. 3, July 2011.

[4] N. M. Pearsall, "PV research and development in Europe - A view from the technology platform," in Proc. 37th IEEE Photovolt.Spec. Conf., June 2011, pp. 200-205.

[5] S. C. Vegunta, P. Twomey, and D. Randless, "Impact of PV and load penetration on LV network voltages and unbalance and potential solutions," CIRED, pp. 10-13, June 2013.
[6] IEEE Guide for Loading Mineral-Oil-Immersed Transformers, Standard C57.91-1995 (R2004).

[7] A. Batman, F. G. Bağrıyanık, Z. E. Aygen, O. Gül, and M. Bağrnyanık, "A feasibility study of grid connected photovoltaic systems in Istanbul, Turkey," Renewable and Sustainable Energy Reviews, vol. 16, pp. 5678-5686, 2012.

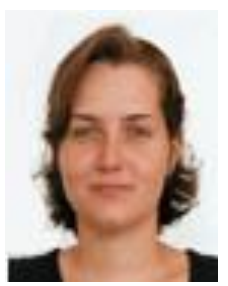

Banu Uçar received the B.Sc. and M.Sc. degrees from Technical University of Istanbul, Turkey in 1996 and 1999 , respectively. She is currently working toward the $\mathrm{PhD}$ degree in electrical engineering at the Electrical Department of Technical University of Istanbul, Turkey. Her research interests are electricity distribution networks, distributed generation and photovoltaic generation.

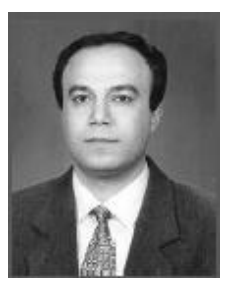

Mustafa Bağrıyanık was born in Turkey, in 1964. He graduated from the Electrical Engineering Department of Istanbul Technical University, Turkey. He obtained both his MSc and $\mathrm{PhD}$ degrees in electrical engineering from Istanbul Technical University. He was a research associate at Texas A\&M, Department of Electrical Engineering. Currently, he is an associate professor in the Department of Electrical Engineering at Istanbul Technical University (ITU), Turkey. His current research interests are power system analysis and application of intelligent methods in electrical engineering. He is a senior member of IEEE and a member of EMO (Turkish Electrical Engineering Society).

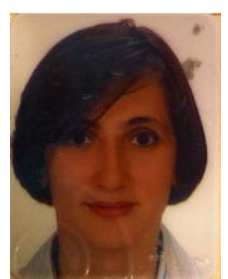

Güven Kömürgöz completed her BS, MS, and $\mathrm{PhD}$ degrees all in electrical engineering at the Istanbul Technical University, Turkey, in 1991, 1995, and 2001, respectively. She is currently an associate professor of electrical engineering. She is interested in heat transfer, numerical methods, design of transformer and electrical machines. 
Clean Energy Technology 
